more this curious murmur is studied, the more will it throw light upon some of the obscurest points in cardiac physiology and pathology.

Glasgow.

\section{INTERESTING CASE OF INJURY OF THE SACRO-ILIAC JOINT OCCURRING IN A CHILD FOUR YEARS OLD.*}

BY JOHN FAGAN, F.R.C.S.I.,

SURGTON TO THE BHLFAST HOSPITAY FOR SICK OHILDREN.

EIEANoR D-, aged four years, was admitted, under my care, into the Children's Hospital, on February 4th, 1875. She presented a most wretched, wan, and pinched appearance; her countenance wore the characteristic expression seen in a child that is exhausted with intense suffering. On examination, I found the left gluteal and sacral regions enormously swollen and of a dark purple colour, the integument tense and glistening, and large tortuous veins ramifying through it. There was wellmarked fluctuation in it, and at one place the skin seemed on the point of breaking.

The history I got from the mother was as follows. About three weeks previous to her admission the child was in perfect health, till one day, standing on a stool placed on top of a box, the lid being old, it gave way, and she fell through with the stool into the box, sustaining an injury somewhere about the hip. The medical man who was treating the case thought it to be one of hip disease, and, seeing it assume the very serious character it did, recommended the mother to take it to the hospital.

The treatment I employed in this case was as follows. After giving the child some wine, I introduced the needle of the aspirator into the abscess where the skin was soundest, and drew off about fourteen ounces of thin unhealthy pus; this relieved the tension very much, and I should say removed about half the quantity of fluid from the sac. The child was then put to bed, and got for nourishment six ounces of wine, an ounce of brandy, two eggs, and milk ad lititum in the twenty-four hours. The next day I again used the aspirator, and removed nearly as much pus of the same character as the day before. The nurse drew my attention at this stage to a small lump in the groin, which looked and felt somewhat like an enlarged gland. In a few days this got much larger, and conveyed a distinct sense of fluctuation. The use of the aspirator on two occasions, taking away about three ounces of pus the first time and an ounce and a half the next, completely removed the swelling. On the 24th of February, just twenty days after her admission, I required to use the aspirator for the last time. For several days previous to this the swelling in the groin had disappeared, and that over the sacrum was getting less. In all I used the aspirator nine times, and removed about sixty ounces of pus. After emptying the abscess on the three or four last occasions, the walls of the sac collapsed, leaving a deep sulcus between the prominent spinous processes of the sacrum and posterior border of the ilium. This I padded with cottonwool, and used slight pressure by means of strips of adhesive plaster and a bandage round the pelvis. On the 8 th of March the child was sent home quite plump and fat, and able to trot about without the slightest indication of lameness.

This case I consider interesting from a threefold point of view: its diagnoxis, prognosis, and treatment. Acute inflammation of the sacro-iliac joint is, I believe, a very rare affection, probably due to the fact that its position in the body renders it less liable to be exposed to the many causes that give rise to inflammation in other joints, as also to the fact that it is the nearest approach to an immovable joint. That it is more likely to occur in childhood is owing no doubt to this joint possessing a delicate synovial membrane during that period, and consequently apt to take on inflammatory action when subjected to any undue violence. That the suppuration about the joint was the result of the injury sustained by the child when she fell through the box * Read before the Ulster Medical Society. there can be no doubt, but the exact nature of the affection was a very puzzling point to make sure about, at least when first I saw the child. As I pointed out to some students who were present when the child was admitted, there were symptums about the case that would warrant one in diagnosing it as a case where the hip-joint or sacro-iliac joint was engaged, or a severe contusion of the muscular structure about these parts, or a combination of all three. Although the case was treated by a medical man as one of hip-joint disease (according to the nrother's statement) there were but very few symptoms pointing to that condition, and those of a character that might arise from other causes. The thigh was flexed on the pelvis and adducted, and there was great pain on attempting to rotate the limb-symptoms likely to be present in disease of either of the joints; while the position of the abscess, the rapid course of the affection, and most particularly the absence of pain when the great trochanter was pressed upon, gave the strongest presumptive evidence that the hip-joint was not the seat of lesion in this case.

The opinion I expressed at the time was, that it was a large abscess resulting from a severe contusion of the muscular structure, and as the child suffered great pain when the sacrum or ilium was pressed upon, that probably there was some inflammation of the sacro-iliac joint. A few days afterwards the appearance of the swelling in the groin confirmed my diagnosis. The matter made its way from the joint under the iliac fascia, and, following the course of the iliacus muscle, made its appearance at the site usually occupied by a psoas abscess.

As regards prognosis, I was at first disposed to give a most unfavourable one, and would look on the case as hopeless but that I had great faith in the recuperative powers of children when placed under favourable conditions. The rapidity and completeness of the cure in this instance would dispose me to give a favourable prognosis in cases of an acute character, with some reservation, however, as all such might not be expected to terminate in so satisfactory a manner as the one under consideration. I have met with cases of disease of this joint occurring in ill-conditioned strumous children, some of which I have under my observation at present, and hope to give the history of them at some future time. The prognosis in their case must naturally be of the most gloomy character.

The treatment I employed was rest, stimulants, light nutritious food, and the use of the aspirator. Of the latter instrument I cannot speak too highly. In cases such as the one $I$ have just described it is invaluable. I have now been in the habit of using it constantly for the past three years, and can safely say that it has never done any harm; that it may occasionally disappoint one, but that in the majority of suitable cases it is the only instrument a surgeon should use who studies the well-being of his patient, as well as his own comfort.

\section{CASE OF PULMONARY COLLAPSE CAUSED BY HAMOPTYSIS; DIFFICULTY OF DIAGNOSIS.}

BY MARK LONG, M.D.

Føв. 17тн, 1875. - Late last night, my partner, Dr. Gibbings, saw for me Miss $G$-, who had expectorated a large quantity of florid blood. She is twenty jears of age, well nourished, robust-looking, and of rather florid complexion. She has had no cough or other illness, nor has she lost flesh recently. Indeed she has not needed medical advice since she first came under my care about two years ago. She was then suffering from debility and shortness of breath, which I found to be due to valvular cardiac disease. Her last illness before this was about three years previously, when she had a severe attack of typhoid fever. There is no trace of consumption on either her father's or mother's side. I found her to-day looking anxious and depressed, and still bringing up small quantities of bright blood, with a slight but frequent cough. She is taking a mixture containing liquid extract of ergot and gallic acid, ice, and cold fluid nourishment. The old loud presystolic murmur is 
audible over the greater part of the left side of the chest, and large crepitation is heard in both lungs anteriorly.

March 2nd. - The hwonorrhage gradnally subsided, and had for some time quite disappeared, until last night, when, after a violent fit of coughing, she brought up about eight ounces of blood.

3rd.-Small quantities of florid blood are expectorated each time she coughs. Pulse 100. Heart's action rather tumultuous. Ordered a belladonna plaster.

4th.-The blood now brought up is rather darker, but still bright. Pulse 96. Heart's action rather quieter. On inspecting the chest, a distinct sinking is apparent under the left clavicle; all the upper part of the left lung is absolutely dull on percussion, and is nearly motionless on the fullest inspiration, in marked contrast to the right side, which is quite resonant and expands freely. No respiratory murmur can be heard in the supra- or infra-clavicular region on the left side, but loud bronchial breathing is audible in one spot to the left of the steruum in the infra-clavicular region. Dr. Munk saw the case with me to-day in consultation, and fully confirmed the presence of the above symptoms. He suggested the administration of five minims of tincture of digitalis and ten minims of the liquid extract of ergot, three times a day.

5th.-No alteration in the physical signs. Pulse 100 ; temperature $998^{\circ}$.

6 th.-Brought up some very dark blood this morning. Dulness unaltered; no vesicular murmur; slight expansion on inspiration.

7 th.-Dulness not so absolute; slight respiratory murmur; expectorated more dark blood.

8th.- Vesicular murmur rapidly increasing, and dulness diminishing; more dark blood brought up.

19th.-Since last date the patient has steadily improved, and there is now no infra-cluvicular sinking, and no difference can be detected between the right and left apices with regard to percussion note, vesicular murmur, or expansion during inspiration.

Remarks. - This case was a most interesting one from a diagnostic point of view, and also with regard to prognosis, as the patient's friends were most anxious for a positive opinion as to the presence of lung disease, and Dr. MIunk and myself could not venture to give more than a guarded one. All the local physical signs of phthisical consolidation were present, and, upon any other supposition, it was diffcult to account for them all, especially the infra-clavicular sinking, which was very marked; but considering the very good family history of the patient, and her condition for some time previous to the attack, I formed the opinion that there must be some other explanation. Pneumonia would have accounted for all the other signs, but not for the infraclavicular depression; the same may be said of "pulmonary apoplexy." I was therefore led to the conclusion that most probably collapse of the upper part of the lung had been caused by the frequent expirations of a violent fit of coughing nearly emptying the pulmonary air-vesicles, and by a sudden inspiration then sucking a quantity of blood or perhaps a clot into the main bronchus, and thus shutting off the air from the vesicles beyond it. Such an occurrence would account not only for all the signs due to consolidation, but also for the sinking of the thoracic wall, which was of course more evident from its proximity to the unyielding clavicle. I think the progress of the case proves the correctness of this opinion, as the abnormal physical signs gradually disappeared according as clots of dark blood were expectorated.

The above case seems to me to be worth publishing, first on account of its diagnostic interest, and, secondly, because I have not found hæmoptysis mentioned as even a possible cause of pulmonary collapse in any of the books I bave at hand, and I have consulted Aitken, Tanner, Watson, Walshe, and Niemeyer.

Amburst-road, Hackney.

Vivisection.--The Royal Commission on Vivi. section held a preliminary meeting in one of the Committee-rooms of the House of Lords on Wednesday. There were present:-Viscount Cardwell (chairman), Lord Winmarleigh, Mrr. W. E. Forster, Sir John Karslake, Mr. J. E. Erichsen, Mr. R. H. Hutton, and the secretary, Mr. N. Baker.

\section{g. attintor}

\author{
HOSPITAL PRACTICE, \\ BRITISH AND FOREIGN.
}

Nulla autem est alia pro certo noscendi via, nisi quamplurimas et morborum et dissectionum historias, tum aliorum, tum proprias collectas babere, et inter se comparare.-MongdGir De Sed.et Caus. Morb., lib. iv. Procemium.

\section{UNIVERSITY COLLEGE HOSPITAL.}

TWO CASES OF SLOUGHING OF ARTERIES. (Under the care of Mr. HEATH.)

THougr the two following cases-for the notes of which we are indebted to Mr. J. R. Godlee, surgical registrarboth terminated fatally, they have one point in common which is of some rarity and interest, and worthy to be placed on record. In both instances considerable sloughing of the principal artery of the limb took place, leading to secondary bæmorrhage; but in neither case was the bleeding so great as to be the immediate cause of death, and in the first case the bæmorrhage occurred only once, sixteen days before death.

J. B-, a woman aged twenty-eight, was admitted on Feb. 3rd, 1875, with a small cystic tumour on the outer side of the leg, three inches below the knee-joint. It was first noticed a year before, and had on one occasion been emptied by an aspirator, when a transparent sticky fluid escaped. 'The cyst was removed by Mr. Heath on Feb. 24th, when it was found to have a very thin wall, and to contain a glairy, clear fluid, closely resembling that which forms the contents of an ordinary ganglion. No difficulty was experienced in the operation, the connexion between the walls of the cyst and the surrounding tissues being at no part at all firm. Silver sutures were placed in the wound and a dry dressing applied, but in three days (Feb. $27 \mathrm{tb}$ ), after a slight rigor, the temperature had risen to $1034^{\circ}$, and an angry blush, accompanied by great œdema, occupied the leg, while the glands in the groin became enlarged and painful. The pain was most severe around the knee-joint, especially on the inner side and in the popliteal space; but though a considerable amount of fluid occupied the joint at one time, none could be discovered in the first few days. By the 18th of March the sense of fluctuation in the knee-joint itself was no longer perceptible; but it became clear, as indeed had been suspected for some time, that there was a collection of matter at the inner part of the thigh. About two ounces of pus were removed with the aspirator, and on the 20th of March a free incision on the outer side of the limb gave vent to about four ounces of dark pus, and showed that there was an extensive abscess beneath the muscles surrounding the bone. The temperature had up to this time kept at abont $101^{\circ}$, and the patient was already much exhausted. After the opening of the abscess the discharge became very profuse, and the weakness of the patient increased proportionately; she assumed a sallow and careworn appearance, was unable to take her food, and enaciated rapidly. The temperature varied from $98^{\circ}$ to $103^{\circ}$, but was of ten high. On the 26 th of April death occurred; but before this three important facts had been observed. On the 25th of March it was noticed that on holding up the limb by the beel great distortion occurred at the knee, and that the leg could in fact be bent at a very considerable angle with the thigh either forwards or laterally; on April 10th very copious hæmorrhage took place from the incision, which appeared to be arterial, and was stopped by a solution of perchloride of iron; and lastly, on April 20th, it was noticed that several of the toes were becoming gangrenous, and that no pulse could be felt either in the anterior or posterior tibial artery.

At the post-mortem examination the knee-joint was found to be completely disorganised, and to communicate by several openings with the large abscess in the thigh, which burrowed beneath the muscles in all directions, and joined the incision made in the removal of the tumour. The tibio-fibular articulation, though much inflamed, did not appear to be opened. The popliteal artery lay exposed in 